\title{
The Manipulative Discourse of Gandalf
}

\author{
Farid Mohammadi \\ E-mail:safm27@yahoo.com
}

Received: 06-02-2014

Accepted: 18-03-2014

Published: 01-07-2014

doi:10.7575/aiac.ijalel.v.3n.4p.110

URL: http://dx.doi.org/10.7575/aiac.ijalel.v.3n.4p.110

\begin{abstract}
The aim of this essay is to investigate discursive, cognitive and social aspects of manipulation in regard to the dialogues of the literary fictional character of Gandalf in the trilogy of The Lord of the Rings. Accordingly, the researcher has taken a multidisciplinary approach to an account of discursive manipulation, and focuses on the cognitive dimensions of manipulation. As a result, the researcher demonstrates meticulously how manipulation involves intensifying the power, moral superiority and the credibility of the speaker(s), while abusing the others (recipients), along with an emotional and attractive way of expression, and supplemented by reasonable facts and documents in regard to a specific issue.
\end{abstract}

Keywords: Manipulation, Discourse, Cognitive, Power Abuse, Persuasion, Social representation, J.R.R. Tolkien

\section{Introduction}

Manipulation is one of the notions that can be categorized in the class of discursive power abuse, it is one of the most important concepts that belongs to the field of Critical Discourse Analysis (CDA). As a matter of fact, Critical Discourse Analysis is an interdisciplinary approach, which analyzes and studies the discourses that consider language as a form of social practice, and systematically investigates how the social and political dominations are reproduced and recreated in written text and talking. In this paper, the researcher investigates specific types of manipulation inside the framework of triangulation, which will connect and study discourse, cognition, and society (Van Dijk, 2001). It should be noted that, applying discourse analytical approach is the most appropriate task to obtain, because manipulation occurs in the written text and talk, and the people, whose minds are being manipulated by manipulators are human beings, therefore, a cognitive analysis is also a necessary factor and useful to understand the process of manipulation; for, indeed this process happens in their minds. Furthermore, social approach is also worthy of investigation, because manipulation indicates illegitimate mind control, and a process of talk-in-interaction. Accordingly, it is very important to include all analytical interpretations of discourse, cognition and society in the way of analyzing manipulation; that is why concerning discourse analytical approaches, Teun A. Van Dijk asserts several times that these three approaches cannot be decreased and reduced to one or two of them (Van Dijk, 1998, 2001). Indeed, social, interactional and discursive approaches are important and necessary; however, a cognitive investigation is also important in its turn, because the process of manipulation is mental.

In this essay, the researcher studies communicative or symbolic type of manipulation, which is a kind of interaction, such as the manipulation, exercised by politicians or by mass media to control and to shape the people's mind, through some kind of discursive persuasions and influences. It is worth mentioning that analyzing the discourses of fictional literary characters in regard to the fields of manipulation and power abuse in both areas of speech act theories and Tolkien studies are very new. Accordingly, this study examines the discourses of a fictional character of Gandalf, the wise old wizard in some series of dialogues towards Bilbo Baggins, and his young cousin Frodo Baggins, to study the different strategies, used by Gandalf through his dialogues.

Consequently, the researcher shall proceed as follows. In section one, he states a brief explanation of the main points concerning the importance and the use of the triangularly approach. In section two, he shall explain about the theoretical aspects of this study. In section three, he shall talk about the significance of this study. In section four, he shall discuss the view of methodology, including types of manipulation and its relation with society, cognition, and discourse. In section five, he will examine the two examples of well-known manipulative discourses, spoken by Gandalf, and investigate his manipulative discourses. In addition, the researcher shall talk about what has he done and what he has achieved in his investigation, in the last and final section.

\section{Theoretical Framework}

As it has been discussed previously, the type of manipulation that will be discussed in this paper is a communicative and interactional practice; it means that a manipulator exercises control over the other people, and it will be more than a simple persuasion; it should be said that it is usually against the will or the best interests of the hearers, but they do not have any idea about it. Thus, it can be said that it has a negative concept, because that kind of action violates the freedom of choice and the social rights. Additionally, manipulation consist of misuse of power (abusive power towards the others), to dominate the hearer(s). it means that it is the exercise of a kind of illegitimate influence and authority towards the others, by means of discourse, so that to make the people believe, accept, behave, and act 
according to some ideas, belong to the ideology of a manipulator; therefore, they will act according to the interest of the manipulator and against the interest of themselves (Chouliaraki, 2005, Martín Rojo and Van Dijk, 1997). In fact, if one wishes to venture and to investigate different types of manipulation, he/she can categorize the mass media such as movies, music and pictures in the group of forceful and illegitimate dominance and influence towards the others in a semiotic sense of manipulation (Van Leeuwen, 2005).

However, it is perhaps fair to assume that manipulation is not always a negative aspect, sometimes, manipulation can be considered as a type of legitimate action, for the greater good of a country, or the majority of people, or an important issue; for instance, in persuasion, the interlocutors are not forced to accept; on the contrary, they are free to believe or to act, according to their own choices, whereas in manipulation, hearers have a more passive role, and they do not have any other choice to reject the speaker's ideology. Indeed, the most negative aspect of a manipulative discourse happens when the hearers are unable to understand and to comprehend the real motives and intentions behind words of the speaker, or to have a bigger picture of that specific issue, to realize the consequences of the aims and plans, expressed by the speaker (manipulator); this is the case of those people, who do not have enough knowledge and perception to find the real intentions, in order to stand and to resist against the manipulations (Wodak, 1987). Van Dijk, in his Elite Discourse and Racism asserts that a well-known example is governmental and/or media discourses concerning the immigration and immigrants issues; it means that to cover their own shortcomings, concerning the bad state of economy, unemployment, and less job opportunities, authorities create a situation, to persuade the ordinary citizens to put the blame on immigrants, and in this way, the majority of people will not really blame the government's policies (1993). To pursue his investigation, the researcher should assert that he follows a multidisciplinary framework, which will investigate the social, cognitive and discursive factors (see, e.g., Van Dijk, 1998, 2001, and 2005). It should be noted that, manipulation is a social phenomenon because it involves the interaction and the misuse of authority and power between the people in a society. Furthermore, manipulation is a cognitive phenomenon, because it always implies the manipulation of the minds of the hearers (participants); and it is most definitely, a discursive and semiotic phenomenon, for it is being exercised through texts, talking and visual messages. As a result, as Van Dijk (2005) claims, it will reduce the credibility and the results of an analytical investigation; in this specific case, if one of these approaches is ignored and reduced, then undoubtedly, all the three point of views are necessary to put manipulation under a meticulous study.

\section{Purpose of the Study}

It is perhaps fair to assume that there is no previous study, in regard to the specific subject of this paper; in point of fact, it seems that most of the previous studies on speech act have been accomplished on different kinds of speech acts, such as Request (Belza, 2008), Apology (Maradani 2010), Compliment (wolfson, 1981), Refusal (FelixBrasdefer, 2008), among which, speech acts of Persuasion and Manipulation have received scant attention. Thus the researcher decided to focus and examine discursive, cognitive and social aspects of manipulation, in regard to the dialogues of the literary and fictional character of Gandalf, in the trilogy of The Lord of the Rings. Therefore, he will analyze the social and cognitive contexts of manipulative discourse, in relation to some specific constraints aspects, such as the dominant position of the manipulator, the recipients' lack of knowledge of the speaker's hidden intention, and the situation in which the consequences of the act of manipulation are in the interest of the dominant group that will lead to the illegitimate social inequality. The present study aims to address the following questions:

1-To what extent and how does a literary figure, (i.e. Gandalf) exercise a manipulative discourse?

2-Is there any practice of classic manipulative strategies, negotiated by Gandalf?

\section{Methodology}

At first, in regard to manipulative discourse, the researcher intends to investigate the social environment of this everyday phenomenon. In point of fact, manipulation involves power and domination, and this in itself, involves interaction between social actors or groups, who exercise this phenomenon over the others (Clegg, 1975; Luke, 1989; Van Dijk, 1989: Wartenberg, 1990). As it has been discussed previously, the complex process of domination and control, at first begins with the control of the mind of the recipients; specifically, it is targeting the beliefs and ideologies of the recipients, so that to take control of their actions, indirectly, rather than an explicit and direct action. However, the question is, what are the conditions of reaching that certain stage? The answer is that the speaker(s) (social actors, a group of people, who possess social power and authority) need to have a perfect public image of a benefactor and the guardian of the society' hence, this will enable them to influence the others (masses of people). It is worth noting that the researcher will limit his analysis to the social criteria, and consequently, he shall ignore the influences of psychological factors, such as knowledge, intelligence, and other aspects of one's personality.

\subsection{Manipulation and Society}

There are certain aspects that can define authority, and clarify the status of the group of men, who are exercising power. For instance, in a family, as a small society, the parents can manipulate the family members because of their highest position in that family, which give them power and authority; the directors in the companies can manipulate their employees, to follow their specific aims and plans, because of their higher business position; in like manner, religious leaders can manipulate their followers, to obey religion in certain specific aspects for the benefit of religion, and politicians can do so in order to gain more votes. Therefore, social manipulation can be defined as a social domination toward the people who have less power, knowledge and authority. Moreover, in order to exercise that kind of power abuse, one requires to have access to some chains of media recourses; for instance, having access to TV, 
internet, books, and magazines, to be able to manipulate as many, and as much as possible. However, that social manipulation might be illegitimate in certain points or on the contrary, legitimate in some aspects. For instance, according to Grice's maxims (1975), conversations should be clear, truthful, relevant, and perhaps complete and informative enough; however, in reality these maxims are often being ignored, because they are difficult to apply; people often lie, or tell just half of a story, and sometimes their arguments and words are mixed with irrelevant point during interactions. As a result, violating all Grice's maxims can be another reason for considering manipulation as a wrong and illegitimate practice of power.

\subsection{Manipulation and Cognition}

In order to distinguish and to differentiate manipulation from other types of mind managements such as teaching, persuasion -which can be considered as having legitimate influences- and to help ease the ways of comprehension that aim to increase individuals' knowledge, one should be aware that in this specific type of mind management, social actor intends to change the people's idea, and sometimes adds opinions and ideologies in individuals' minds to take control of their actions, as well as their behaviors, according to their own interest. But how can discourse affect and change people's mind? There are indeed various numbers of cognitive studies that reveal and clarify how understanding can be influenced by numerous contextual or textual manipulations; however, because of the lack of time and space, this essay faces certain constraints and the researcher shall not cover all the aspects.

\subsubsection{Manipulating Short Term Memory}

Short term memory (STM) can be defined as the capacity for storing a small amount of data and information in mind in an active, readily available state for a short period of time. It is worth noting that both discourse in general and manipulative in particular, involve processing information in short term memory (STM). In fact, comprehending texts, utterances and non-verbal signs, signals and symbols can be considered in this category. Interestingly, this process is a very important and strategic tool for social actors, and speakers. For example mind can remember and comprehend some texts and fonts, which are written in bold, larger seize with attracting colors, in study books, advertisements, presidential candidacy, or other intended aims. Thus the intended short message(s) will be kept in mind longer than usual time and will be recalled in a very shorter time. It is perhaps fair to say that this process happens in both manipulation, and contrarily in legitimate types of communications, for instance in study books, newspapers, news and other genres. Hence, Van Dijk asserts that, cognitively speaking, manipulation is nothing special: it makes use of very general properties of discourse processing (2005).

It is worth mentioning that in order to analyze manipulation and, to make a boundary between legitimate and illegitimate force in exercising discourse, some other criteria are also needed. In cognitive analysis, we have been informed how people are manipulated by controlling their minds; however, the problem is that there is no such specific pattern or analytical statement to express that it is wrong! Similarly, this can be said about the other forms of non-verbal expressions, such as the use of specific colors, images, signs in written conversations, gestures, body language, especially, face work. Therefore, as discourse comprehension in STM, deals with different types of analysis such as lexical operations, syntactic, morphological and phonological operations, all can be influenced by other factors, such as high-volume speaking, aggressive or none aggressive choice of words, slow pronunciation, using simple and less complex words, to make the recipients understand and react better. Interestingly, the opposite case is also possible, when the speakers intend to make the people understand less; therefore, they try to speak faster, making complex sentences to be less clear, with more complex words, in order to talk about a confusing and problematic topic. Perhaps it is worth mentioning that STM manipulation is one of the most favorite strategies to manipulate the others.

\subsubsection{Episodic Manipulation}

It is very important that the recipients have a specific topic in their mind, so that they understand the intended discourse of the manipulator; in other words, the intended discourse should restrict their freedom of interpretation, so that the hearers comprehend the discourse, according to the interest of the manipulator. To pursue this aim, the speaker should construct and make mental model in episodic manipulation, in means that according to his benefit, the speaker should engage the hearers' own experiences, but with controlled freedom. For instance, to gain a positive answer from a group of people, the speaker should speak about their good deeds, and discursively shift and deemphasize those details that are inconsistent with their interests, such as the details of their less good actions, and firmly find another person or group to put the blames on him/them. Therefore, in this strategy the speaker should construct his ideas, according to some well-comprehended episodic memories, ideologies, and accepted social norms of the hearers.

\subsection{Discourse}

In general, manipulation will be negotiated and performed through discourse; however, it also consists of other aspects, such as non-verbal characteristics; for instance, body language, the text layout, images, sounds and other aspects. It is worth noting that discourse in general is not manipulative, but the tools and strategies that can be used inside the realm of discourse can make it manipulative. However, in some cases, manipulation as a social practice of power cannot be manipulative for, the recipients are different with different ideology, or the particular time was not appropriate to exercise manipulative tools, and so on. Thus, although discourse structures in general are not manipulative, but there are some aspects that can be influential in affecting the minds of the others. Van Dijk (2003, 2006) holds that these specific strategies are influential to manipulate the others: 
1. Overall interaction strategies

\subsection{Positive self-presentation}

1.2. Negative other-presentation

2. Macro speech act implying Our 'good' acts and Their 'bad' acts, e.g. accusation, defense

3. Semantic macrostructures: topic selection

3.1. (De-) emphasize negative/positive topics about Us/Them

4.1. Local speech acts implementing and sustaining the global ones, e.g. statements that prove accusations

5. Local meanings our/their positive/negative actions

5.1. Give many/few details

5.2. Be general/specific

5.3. Be vague/precise

5.4. Be explicit/implicit

6. Lexicon: Select positive words for Us, negative words for Them

7. Local syntax

7.1. Active vs passive sentences, nominalizations: (de)emphasize Our/Their positive/negative agency, Responsibility

\section{Rhetorical figures}

8.1. Hyperboles vs euphemisms for positive/negative meanings

8.2. Metonymies and metaphors emphasizing Our/Their positive/negative properties

9. Expressions: sounds and visuals

9.1. Emphasize (loud, etc.; large, bold, etc.) positive/negative meanings

9.2. Order (first, last: top, bottom, etc.) positive/negative meanings

Accordingly, these strategies, moves (and reactions) at various levels of discourses are hardly surprising, because they implement the usual ideological square of discursive group polarization (de/emphasize good/bad things of Us/Them) one finds in all ideological discourse (Van Dijk, 2003, 2005). As it has been discussed previously, it should be noted that discursive strategies are not only used in the means of manipulation, but also discursive strategies are being used in different situations, events and periods by different people, with different ideological intentions, in search of gaining specific results. Interestingly, in some series of legitimate communications such as persuasions, education, helping the others to comprehend better, people use the same discourse structures that can be used in illegitimate and abusive forms of communications. However, in every specific situation, and according to the needs, aims, and social norms, and especially the intention(s) of the speaker, one or few of these specific strategies can be preferred in their manipulation. Van Dijk (2003) introduces a contextual criterion that recipients of manipulation, may be categorized and defined as victims, which means that they can be regarded as some people who are lacking crucial perception and knowledge of what the real intention is, and how to resist, detect or avoid manipulation. This may involve:

1. Incomplete or lack of relevant knowledge, so that no counter-arguments can be formulated against false, incomplete or biased assertions.

2. Fundamental norms, values and ideologies that cannot be denied or ignored.

3. Strong emotions, traumas, etc. that make people vulnerable.

4. Social positions, professions, status, etc. that induce people into tending to accept the discourses, arguments, etc. of elite persons, groups or organizations.

These four items are the typical aspects of the cognitive, emotional and social situation of a communicative interaction. Furthermore, it is perhaps useful to mention that in order to exercise a successful manipulation, the speaker should have a similar mentality of the perception and a mental model of the recipients, such as their way of thinking, ideologies, emotions, and so on. However, it is not necessary for the speaker to manipulate all the recipients and hearers, rationally it is acceptable for the manipulator, to pursue his aim over a large group of people. Furthermore, there are some structures that can be focused on every context and situation, Van Dijk, (2003), explains that concerning the varieties of contexts, these structures can be categorize as:

1. Emphasize the position, power, authority or moral superiority of the speaker(s) or their sources, and where relevant, the inferior position, lack of knowledge, etc. of the recipients.

2. Focus on the (new) beliefs that the manipulator wants the recipients to accept as knowledge, as well as on the arguments, proofs, etc. that make such beliefs more acceptable.

3. Discredit alternative (dissident, etc.) sources and beliefs. 
4. Appeal to the relevant ideologies, attitudes and emotions of the recipients.

Admittingly, it is worth mentioning that these general strategies of manipulative discourse seem to be more semantic, because the focus on manipulation exist on the scale of the content of a written text and talking. Hence, some specific speech acts, such as the manner of the expression of the manipulators (intonation, volume, speed), and the use of metaphors and rhetorical figures, and the status and the social class of the manipulators are very influential to manipulate the recipients.

\section{Results}

In this section the researcher shall study the two examples, extracting from the trilogy of The Lord of the Rings, which can be regarded as two well-known manipulative discourses. In order to investigate and study the previously mentioned manipulative discourse strategies, it is appropriate to mention that the researcher for the first example, bring a part of the story, where Bilbo Baggins is ready to leave the Shire after his 111 birthday party, but Gandalf is questioning him toward the Ring and at first tries to persuade him to give up the Ring, however Bilbo resists, therefore, Gandalf has to manipulate his old friend Bilbo to give up the Ring and leave it to his nephew, Frodo:

“...I am leaving everything to him, of course, except a few oddments. I hope he will be happy, when he gets used to being on his own. It's time he was his own master now." "Everything?" said Gandalf.

"The ring as well? You agreed to that, you remember."

"Well, er, yes, I suppose so," stammered Bilbo.

"Where is it?"

"In an envelope, if you must know," said Bilbo impatiently. "There on the mantelpiece. Well, no! Here it is in my pocket!" He hesitated. "Isn't that odd now?" he said softly to himself. "Yet after all, why not? Why shouldn't it stay there?"

Gandalf looked again very hard at Bilbo, and there was a gleam in his eyes. "I think, Bilbo," he said quietly, "I should leave it behind. Don't you want to?" "Well yes - and no. Now it comes to it, I don't like parting with it at all, I may say. And I don't really see why I should. Why do you want me to?" he asked, and a curious change came over his voice. It was sharp with suspicion and annoyance. "You are always badgering me about my ring; but you have never bothered me about the other things that I got on my journey."

"No, but I had to badger you," said Gandalf. "I wanted the truth. It was important. Magic rings are well, magical; and they are rare and curious. I was professionally interested in your ring, you may say; and I still am. I should like to know where it is, if you go wandering again. Also I think you have had it quite long enough. You won't need it any more. Bilbo, unless I am quite mistaken.” "Yes, yes," said Gandalf. "But there is no need to get angry." "If I am it is your fault," said Bilbo. "It is mine, I tell you. My own. My precious. Yes, my precious."

The wizard's face remained grave and attentive, and only a flicker in his deep eyes showed that he was startled and indeed alarmed. "It has been called that before," he said, "but not by you."

"But I say it now. And why not? Even if Gollum said the same once. It's not his now, but mine. And I shall keep it, I say."

Gandalf stood up. He spoke sternly. "You will be a fool if you do. Bilbo," he said. "You make that clearer with every word you say. It has got far too much hold on you. Let it go! And then you can go yourself, and be free."

"I'll do as I choose and go as I please," said Bilbo obstinately.

"Now, now, my dear hobbit! " Said Gandalf. "All your long life we have been friends, and you owe me something. Come! Do as you promised: give it up!" 
“Well, if you want my ring yourself, say so!" cried Bilbo. "But you won't get it.

I won't give my precious away, I tell you." His hand strayed to the hilt of his small sword.

Gandalf's eyes flashed. It will be my turn to get angry soon, "he said. If you say that again, I shall. Then you will see Gandalf the Grey uncloaked.” He took a step towards the hobbit, and he seemed to grow tall and menacing; his shadow filled the little room.

Bilbo backed away to the wall, breathing hard, his hand clutching at his pocket. They stood for a while facing one another, and the air of the room tingled.

Gandalf's eyes remained bent on the hobbit. Slowly his hands relaxed, and he began to tremble.

"I don't know what has come over you, Gandalf," he said. "You have never been like this before. What is it all about? It is mine isn't it? I found it, and Gollum would have killed me, if I hadn't kept it. I'm not a thief, whatever he said." "I have never called you one," Gandalf answered. "And I am not one either. I am not trying to rob you, but to help you. I wish you would trust me, as you used." He turned away, and the shadow passed. He seemed to dwindle again to an old grey man, bent and troubled.

Bilbo drew his hand over his eyes. I am sorry, he said. "But I felt so queer. And yet it would be a relief in a way not to be bothered with it any more. It has been so growing on my mind lately. Sometimes I have felt it was like an eye looking at me. And I am always wanting to put it on and disappear, don't you know; or wondering if it is safe, and pulling it out to make sure. I tried locking it up, but I found I couldn't rest without it in my pocket. I don't know why. And I don't seem able to make up my mind."

"Then trust mine," said Gandalf. "It is quite made up. Go away and leave it behind. Stop possessing it. Give it to Frodo, and I will look after him." (The Fellowship of the Ring, 45-47)

As a matter of fact, Gandalf exercised almost all strategic tools to manipulate his old friend to give up the One Ring, which was absolutely against the interest and heart desire of Bilbo. Gandalf, at first, showed positive selfrepresentation by allowing Bilbo to speak and to express his inner thoughts. However, Gandalf shows that he has the right to question him, and mentions that the decision (that is, giving up the Ring) had been made a few years ago. He also tries to represent himself as a positive, friendly figure to Bilbo; he reminds him that they are old friends, and that he was always present to help him, and not to rub him!

Bilbo is still resisting; and he does not show any sign of being persuaded; therefore, Gandalf, with non-verbal expressions, such as face work and angry eyes, presents his power and authority toward him, and verbally expresses his might and higher status to him, and repeats his expressions of doubts and suspicion toward the Hobbit. In his next move, Gandalf tries to discredit the opponent (Bilbo) in that situation, and he tries to rationalize his constant badgering, by asking him to give up the Ring. After that move, Gandalf shows another side of himself (after showing his power and authority), by emotionalizing the argument, and by repeating that he is Bilbo's friend, so that he may regain Bilbo's trust; and he emphasizes that he is not his enemy, and that his only intention is to help him. In fact, in regard to Van Dijk's (2003, 2006) strategic hypothesis for manipulation, Gandalf tries to show a positive figure of himself with moral superiority by (allowing him to debate, showing him respect, etc.). Thus, he tries to rationalize his doubts over Bilbo, discrediting him, and he finally tries to emotionalize (melodramatize) the situation by letting him remember that he is not his enemy by any means.

Now consider the next part of Gandalf's discourses toward Frodo. Outside the linguistic scope, we know that Gandalf has already chosen Frodo, as the Ring-bearer; Gandalf does not wish to have the Ring, for he knows that it would make a great catastrophe; moreover, he does not trust anyone whatsoever. He knows that persuading Frodo is difficult, especially if he knows the whole truth about the Evil Ring. It is perhaps fair to believe that Gandalf considers what is best and useful for the inhabitants of the Middle-earth in the whole, even if this means that Frodo should be sacrificed for the sake of the others. Furthermore, he exercises a series of strategies, to manipulate Frodo to accept that torturous responsibility, however, without any direct, brutal force: 
"I don't understand," said Frodo.

"You are very mysterious! What are you afraid of?" said Frodo.

"Last night you began to tell me strange things about my ring, Gandalf," he said.

"And then you stopped, because you said that such matters were best left until daylight.

You say the ring is dangerous, far more dangerous than I guess. In what way?"

"In many ways," answered the wizard. It is far more powerful than I ever dared to think at first, so powerful that in the end it would utterly overcome anyone of mortal race who possessed it. It would possess him.

"In Eregion long ago many Elven-rings were made, magic rings as you call them, and they were, of course, of various kinds: some more potent and some less. The lesser rings were only essays in the craft before it was full-grown, and to the Elven-smiths they were but trifles - yet still to my mind dangerous for mortals.

But the Great Rings, the Rings of Power, they were perilous."

"How terrifying!” said Frodo.

"When did I first begin to guess?" he mused, searching back in memory. "Let me see - it was in the year that the White Council drove the dark power from Mirkwood, just before the Battle of Five Armies, that Bilbo found his ring. A shadow fell on my heart then, though I did not know yet what I feared. I..." "Ever since Bilbo left I have been deeply concerned about you, and about all these charming, absurd, helpless hobbits. It would be a grievous blow to the world, if the Dark Power overcame the Shire; if all your kind, jolly, stupid Bolgers, Hornblowers, Boffins, Bracegirdles, and the rest, not to mention the ridiculous Bagginses, became enslaved."

Frodo shuddered. "But why should we be?" he asked. "And why should he want such slaves?"

"But your safety has passed. He does not need you - he has many more useful servants - but he won't forget you again. And hobbits as miserable slaves would please him far more than hobbits happy and free. There is such a thing as malice and revenge."

"Revenge?" said Frodo. "Revenge for what? I still don't understand what all this has to do with Bilbo and myself, and our ring."

"It has everything to do with it," said Gandalf. "You do not know the real peril yet; but you shall. I was not sure of it myself when I was last here; but the time has come to speak. Give me the ring for a moment."

Gandalf held it up. It looked to be made of pure and solid gold. "Can you see any markings on it?" he asked.

"I cannot read the fiery letters," said Frodo in a quavering voice.

"No," said Gandalf, "but I can. The letters are Elvish, of an ancient mode, but the language is that of Mordor, which I will not utter here. But this in the Common Tongue is what is said, close enough:

One Ring to rule them all, One Ring to find them,

One Ring to bring them all and in the darkness bind them.

He paused, and then said slowly in a deep voice: "This is the Master-ring, the One Ring to rule them all. This is the One Ring that he lost many ages ago, to the great weakening of his power. He greatly desires it - but he must not get it." Frodo sat silent and motionless. Fear seemed to stretch out a vast hand, like a dark cloud rising in the East and looming up to engulf him. "This ring!" he 
stammered. "How, how on earth did it come to me?"

"I wish it need not have happened in my time," said Frodo.

"So do I, said Gandalf, 'and so do all who live to see such times. But that is not for them to decide. All we have to decide is what to do with the time that is given, us. And already, Frodo, our time is beginning to look black. The Enemy is fast becoming very strong. His plans are far from ripe, I think, but they are ripening. We shall be hard put to it. We should be very hard put to it, even if it were not for this dreadful chance.

"I do really wish to destroy it!" cried Frodo. “Or, well, to have it destroyed. I am not made for perilous quests. I wish I had never seen the Ring! Why did it come to me? Why was I chosen?"

"Such questions cannot be answered," said Gandalf. "You may be sure that it was not for any merit that others do not possess: not for power or wisdom, at any rate. But you have been chosen, and you must therefore use such strength and heart and wits as you have."

"But I have so little of any of these things! You are wise and powerful. Will you not take the Ring?"

"No!" cried Gandalf, springing to his feet. "With that power I should have power too great and terrible. And over me the Ring would gain a power still greater and more deadly." His eyes flashed and his face was lit as by a fire within. "Do not tempt me! For I do not wish to become like the Dark Lord himself." the wizard, turning back to Frodo, "the decision lies with you. But I will always help you." He laid his hand on Frodo's shoulder. "I will help you bear this burden, as long as It is yours to bear. But we must do something, soon. The Enemy is moving."

“Well!" said Gandalf at last. "What are you thinking about? Have you decided what to do?"

"I should like to save the Shire."

"My dear Frodo!" exclaimed Gandalf. "Hobbits really are amazing creatures, as I have said before. You can learn all that there is to know about their ways in a month, and yet after a hundred years they can still surprise you at a pinch. I hardly expected to get such an answer, not even from you. But Bilbo made no mistake in choosing his heir, though he little thought how important it would prove." (The Fellowship of the Ring 59-76)

Gandalf tries at first not to give so much information and data about the problem, therefore when he observes his hearer's concern, he starts to talk about the history of the Evil Ring and the aftermath of the previous wars, and how the Dark Lord Sauron transferred much of his Power to his Ring, and how malicious is that Evil Ring... Furthermore, he describes the Ring and how it works. As he continues, by emotionalizing the argument, and by warning that the happy times had passed and that the beloved and beautiful land of the Shire and its peaceful inhabitants are in the danger of destruction and slavery, he exercised that strategy, most seriously and persistently. Accordingly, Gandalf exercised another strategic process to facilitate the understanding of that issue, which was to ask Frodo to look at the Ring, so that he may see the unknown marking and words and read them. Interestingly, by doing so, he typically engages in some form of STM-based manipulation of discourse understanding. Frodo could not read and comprehend the Black speech of Mordor, but Gandalf could read, and read he did, those words. He then makes the mind of the recipient (Frodo), ready to be manipulated, manipulatively.

The speaker (Gandalf), uses another strategic tool, which is an Ideological Polarization (We/The Good people versus Them/The enemy, which is Sauron and his malice forces); and the necessity of being together, and following a plan to stand in front of the enemy, because all of them are in danger of facing an imminent and mortal war, which would bring nothing but utter destruction. After that, Gandalf tries to practice a positive self-presentation, by not accepting the One Ring, although, he intends to use it for the purpose of good; however he does not wish to have it, for he 
knows that he could have become another Dark Lord. Accordingly, by rejecting the Ring, Gandalf simultaneously, emphasizes his power, his authority, and his wisdom, to his recipient, who is none other than the young Hobbit.

It can be said that, although the hearer (recipient) is afraid of all these things, however, he knows that there is no way to escape from the speaker's call to adventure, and he has to accept his silent call. Therefore, when the speaker (Gandalf) finds out that he successfully manipulated Frodo (indirectly, and without any force), he repeats his selfpositive presentation, and persuades him that until the end, it is the recipient's choice, to accept the Ring or to refuse it. Later, by extending his help and his commitment toward Frodo, Gandalf again presents the picture of a concerned leader, who is always available for the recipients. Thus, the mission is accomplished; indeed, he used almost all manipulation strategies to manipulate the recipient. It should be noted that although these two examples did not present and cover the all possible strategies of manipulative discourse, however, the researcher has found some classic examples of manipulative strategies, used by the speaker (Gandalf); for instance, emphasizing one's own power, one's authority and one's moral superiority, by providing details, concerning the facts, polarization between We and the Enemy, positive self-presentation and negative other-presentation, ideological alignment (nationalism, fight and sacrifice for the benefit of the beloved homeland), emotional appeals, and so on.

Bilbo and Frodo are both the victims of manipulation, exercised by Gandalf; however, it is perhaps fair if one assumes that in what way the two Hobbits can be regarded as the victims of manipulation, for Gandalf did not do anything against them. However, it can be asserted that inside the scope of linguistics, Gandalf almost used different manipulative strategies. Furthermore, it should be noted that inside the literary boundaries, in regard to the first instance, it is perhaps fair to assume that, when Bilbo found the Ring, during his adventure, inside the misty mountain, it was his own right to keep the Ring as long as he desired, especially, if we remember that he put his life in danger and that he could have been killed by Gollum or Goblins. Thus, the least was to keep something that he had found for himself, and by which he helped his friends numerous times by using it. The second reason is that he was free to choose what he wanted to inherit to his nephew and what he wished to keep for himself; therefore, when Gandalf indirectly, at first, and directly later asked him to give up the Ring and give it to Frodo, he exercised his domination toward the poor Hobbit. It can be said that Bilbo's resistance was because of the Evil power of the Ring, but he should have not been forced to give it up and it can be considered as an illegitimate action and as a mind control manner toward him; something was against the interest of the recipient, but according to the interest of the speaker. Concerning the second example, the speaker (Gandalf) is one of the most knowledgeable and powerful figures of the Middle-earth, one of the Istari. He perfectly knew how much difficult, and massively dangerous and difficult was to have the Ring, and what could have happened for the Ring-bearer, perhaps a sudden, or a painless death in a best-case scenario! Not to mention that numerous times, he faced "near death experiences", during his mission. In fact, if the young and happy Frodo knew what would happen to him during his initiation, it is perhaps fair to assume that he would have not accepted that difficult task, by any means. That is why Gandalf did not mention the possible future of Frodo, and in other words, by accepting the responsibility of the Ring, he is sacrificing himself, for the interest and the benefit of almost every other creature in the Middle-earth. Accordingly, it is right to assume that Gandalf controlled Frodo's mind; at least, he created a situation, so that Frodo would accept that responsibility, without having clear ideas of what would happen to him. However, it should be noted that in Gandalf's case, his interest was to save the Middle-earth and its inhabitants, so he had no any other choice...

\section{References}

Augoustinos, M. and Walker, I. (1995) Social Cognition: An Integrated Introduction. London: Sage.

Clegg, S. (1975) Power, Rule, and Domination: A Critical and Empirical Understanding of Power in Sociological Theory and Organizational Life. London: Routledge \& Kegan Paul.

Day, N. (1999) Advertising: Information or Manipulation? Springfield, NJ: Enslow.

Dillard, J.P. and Pfau, M. (2002) The Persuasion Handbook: Developments in Theory and Practice. Thousand Oaks, CA: Sage.

Etzioni-Halevy, E. (1989) Fragile Democracy: The Use and Abuse of Power in Western Societies. New Brunswick, NJ: Transaction.

Fairclough, N. (1995). Critical discourse analysis: the critical study of language. London: Longman. PDF.

Grice, H. (1975) 'Logic and Conversation', in P. Cole and J. Morgan (eds) Syntax and Semantics, Vol. 3: Speech Acts, pp. 68-134. New York: Academic Press.

Habermas, J. (1984) The Theory of Communicative Action. Boston, MA: Beacon Press.

Kintsch, W. (1998) Comprehension: A Paradigm for Cognition. Cambridge: Cambridge University Press.

Luke, T.W. (1989) Screens of Power: Ideology, Domination, and Resistance in Informational Society. Urbana: University of Illinois Press.

Messaris, P. (1997) Visual Persuasion: The Role of Images in Advertising. Thousand Oaks, CA: Sage.

Moscovici, S. (2001) Social Representations: Explorations in Social Psychology. New York: New York University Press. 
O’Keefe, D.J. (2002) Persuasion: Theory \& Research. Thousand Oaks, CA: Sage.

Shore, B. (1996) Culture in Mind: Cognition, Culture, and the Problem of Meaning. New York: Oxford University Press.

Tulving, E. (1983) Elements of Episodic Memory. Oxford: Oxford University Press.

Van Dijk, T.A. (1989) 'Structures of Discourse and Structures of Power', in J.A. Anderson

(ed.) Communication Yearbook 12, pp. 18-59. Newbury Park, CA: Sage.

Van Dijk, T.A. (1991) Racism and the Press. London: Routledge.

Van Dijk, T.A. (1993) Elite Discourse and Racism. Newbury Park, CA: Sage.

Van Dijk, T.A. (1996) 'Discourse, Power and Access', in C.R. Caldas-Coulthard and M. Coulthard (eds) Texts and Practices: Readings in Critical Discourse Analysis, pp. 84-104. London: Routledge.

Van Dijk, T.A. (1998) Ideology: A Multidisciplinary Approach. London: Sage.

Van Dijk, T.A. (1999) 'Context Models in Discourse Processing', in H. van Oostendorp and

S.R. Goldman (eds) The Construction of Mental Representations during Reading, pp. 123-48. Mahwah, NJ: Erlbaum. Van Dijk, T.A. (2001) 'Multidisciplinary CDA: A Plea for Diversity', in Ruth Wodak and

Michael Meyer (eds) Methods of Critical Discourse Analysis, pp. 95-120. London: Sage.

Van Dijk, T.A. (2003) Ideología y discurso. Barcelona: Ariel.

Van Dijk, T.A. (2006) Discourse and manipulation. London: Sage Publications.

Van Dijk, T.A. and Kintsch, W. (1983) Strategies of Discourse Comprehension. New York: Academic Press.

Van Leeuwen, T. (2005) Introducing Social Semiotics. London: Routledge.

Wartenberg, T.E. (1990) The Forms of Power: From Domination to Transformation. Philadelphia, PA: Temple University Press. 